\title{
Development of a fluorescent quantitative real-time polymerase chain reaction assay for the detection of
}

\author{
novel-goose parvovirus in vivo \\ Haibin $\mathrm{Ma}^{1}$, Yahui $\mathrm{Li}^{2}$, Junzheng Yang ${ }^{1 *}$ \\ ${ }^{1}$ Bioland Laboratory (Guangzhou Regenerative Medicine and Health Guangdong Laboratory), \\ Guangzhou, 510700, China \\ ${ }^{2}$ Guanzhou high-tech pharmaceutical and food technical school, Guangzhou, 511400, China \\ * Correspondence to Junzheng Yang (yangjunzheng606403@163.com), Bioland Laboratory \\ (Guangzhou Regenerative Medicine and Health Guangdong Laboratory), \\ Guangzhou, 510700, China
}

\begin{abstract}
Objectives: To develop a sensitive, highly specific fluorescent quantitative real-time PCR assay for accurate detection and quantification of novel-goose parvovirus (N-GPV) in vitro and in vivo.

Methods: Specific primers was designed based on N-GPV inverted terminal repeats region; virus RNA (DFV, NDV, AIV, DHV-1, DHV-3) and virus DNA (MDPV, GPV, N-GPV) were extracted, cDNA (DFV, NDV, AIV, DHV-1, DHV-3) were prepared from viral RNAs using M-MLV Reverse Transcriptase, and prepared cDNA (DFV, NDV, AIV, DHV-1, DHV-3) and DNA (MDPV, GPV, N-GPV) amplified by real-time PCR; the sensitivity, specificity and reproducibility of established real-time PCR methods were evaluated, and finally we validated the reliability of real-time PCR methods in duck lings models in vivo.

Results: The standard curve of established real-time PCR had a good linearity (slope was -0.3098, Y-intercept was 37.865, efficiency of standard curve was 0.995); the detection limit of established real-time PCR for N-GPV was 10 copies/reaction. The sensitivity of real-time PCR was 10 copies/ $\mu \mathrm{L}$, which was 1000 times higher than conventional gel-based PCR assay. The results of intra-assay CVs (0.04-0.74\%) and inter-assay CVs (0.16-0.53\%) showed that the real-time PCR assay had an excellent repeatability. This method also could efficiently detect viral load in heart, liver, spleen,
\end{abstract}


lung, kidney, pancreas, bursa of Fabricius, brain, blood and excrement from ducklings models after N-GPV infection from $6 \mathrm{~h}$ to 28 days, which could provided us a dynamic distribution observation of N-GPV viral load using this real-time PCR assay in vivo.

Conclusion: In the study, we developed a high sensitive, specific and reproducible real-time PCR assay for N-GPV detection. The established real-time PCR assay was suitable for parvovirus detection and quantification simultaneously, no matter sample obtained from blood, internal organs or ileac contents; the present work may provide insight into the pathogenesis of N-GPV and will contributes to better understanding of this newly emerged novel GPV related virus in cherry valley ducks.

Keywords: GPV; N-GPV; real-time PCR; short beak and dwarfism syndrome. 


\section{Introduction}

There are several parvovirus duck strain variations on the basis of phylogeny and homology analysis main including GPV (goose parvovirus), MDPV (muscovy duck parvovirus) and N-GPV (novel-goose parvovirus). The structure of GPV and MDPV contain a linear, single-stranded DNA genome (5.0-5.1kb) having two inverted terminal repeats (ITR) at both ends forming a hairpin structure containing stem and bubble region having length 456 and 442 nucleotides for MDPV and GPV respectively ${ }^{[1,2]}$. They have two open reading frames (ORFs), left and right ORFs encode non-structural (NS1 and NS2) and structural (VP1, VP2 and VP3) proteins respectively ${ }^{[3,4]}$.

$\mathrm{N}-\mathrm{GPV}$ is a kind of newly emerged, distinct GPV-related virus usually causes short beak dwarfism syndrome (SBDS) in young ducks. In China, it was reported initially in 2014 and since then it severely affected the duck industry mainly due to reduction in weight of animals and size of beak, there are numerous SBDS outbreaks in mule duck and Cherry Valley duck flocks in various regions of China ${ }^{[5,14]}$. GPV is an etiological agent for Derzsy's disease, mortality rate is $70-100 \%$ during first four weeks, usually resulted in huge economic losses to the duck industry ${ }^{[5,6]}$. Clinically, the disease is characterized by lethargy, stunting, anorexia, locomotor dysfunction, watery diarrhea and death within 3-5 days ${ }^{[7]}$. MDPV characterized clinically by signs almost similar to GPV mainly affects three-week-old Muscovy ducklings ${ }^{[1,8,9]}$. The complete genome sequence of both parvoviruses shares $79.7-85.0 \%$ homology ${ }^{[10}$, $11,18]$.

SBDS caused by novel GPV-related virus (N-GPV) was first reported in France during 1970s in mule ducks ${ }^{[12,13]}$. Adult ducks are found resistant to this disease while young animals infected with N-GPV have swollen tongue, shorter tibia and stunted growth with $2 \%$ mortality rate while morbidity reaches $10 \%-30 \%$ in most cases $^{[15]}$. The losses to the duck industry therefore are mainly due to reduction in weight and size of animals ${ }^{[16]}$.

Real-time PCR is a new technique with remarkable sensitivity, specificity, 
accuracy, reproducibility, visualization of results, simple and less-contamination potential compared to other diagnostic methods, it has become a potentially powerful alternative in microbiological diagnostics ${ }^{[17]}$. In order to effectively prevent SBDS in duck and reduce the economic loss caused by SBDS, combining the advantages of real time PCR, in this article, we developed a fully validated, highly specific and reliable real-time PCR assay for detection of N-GPV infection, and validated effectiveness and specificity of real-time PCR assay in vitro and in vivo.

\section{Methods}

\subsection{Preparation of Virus and PCR template DNA}

N-GPV AH strain was isolated from Cherry Valley duck flock from Anhui province in 2021 in our lab. GPV and MDPV were bought from China Veterinary Culture Collection Center. Duck flavivirus (DFV), Newcastle disease virus (NDV), Avian influenza (AIV), Duck hepatitis virus type 1 and type 3 (DHV-1 and DHV-3), Riemerella anatipestifer ( $R$. a.), Escherichia coli (E. coli.) were stored in our lab.

Viral RNA (DFV, NDV, AIV, DHV-1, DHV-3) and DNA (MDPV, GPV, N-GPV) were extracted using Viral DNA/RNA Miniprep Kit (Axygen, New York, USA), according to the manufacturer's instructions. cDNA (DFV, NDV, AIV, DHV-1, DHV-3) were prepared with viral RNAs using M-MLV Reverse Transcriptase (Promega, Wisconsin, USA). Bacterial genomic DNA ( $R$. $a$. and $E$. coli) were extracted using TIANamp Bacteria DNA Kit (Tiangen, Beijing, China). All DNA and cDNA were stored at $-80^{\circ} \mathrm{C}$ until for use.

\subsection{PCR primer design}

The primers of real-time PCR assay were designed using Integrated DNA Technologies (Primer software, Skokie, Illinois, USA) on the basis of highly conserved regions of N-GPV. The conserved regions having characteristic variation with GPV and MDPV were selected and the primer sequence were shown at Table 1. Primers were verified by Basic Local Alignment Search Tool for specificity analysis and synthesized by Thermo Scientific Co., Ltd. (Guangzhou, China). 
Table 1: Sequences of the primers used in real-time PCR method for N-GPV detection

\begin{tabular}{cccc}
\hline Name & Sequence 5'to 3' & Tm( $\left.{ }^{\circ} \mathrm{C}\right)$ & size (bp) \\
\hline N-GPV- F & CACTTCCTGGCGCGCAAAAT ATTT & 60 & 108 \\
N-GPV- R & TGCGTCACCGGAAGCAC & & \\
\hline
\end{tabular}

\subsection{Preparation of standard plas mid DNA templates}

The DNA templates length of N-GPV (strain AH, GenBank Accession No. MH444513) was 4,639-4,748bp amplified by real-time PCR and conventional PCR. The product was ligated into the pMD-18T vector (TaKaRa, Dalian, China) and transformed into E.coli DH5a competent cells (Tian, Beijing, China). The pMD-18T-ITR was extracted using Plasmid Extraction Minin Kit (Solarbio, Beijing, China) and was used as the standard plasmid. The recombinant plasmid was quantified using a NANO-DROP 2000 spectrophotometer (Thermo Scientific, Waltham, MA, USA). The plasmid copy number was calculated using the equations described by Yun et. al. on the basis of the molecular weight ${ }^{[19,20]}$.

\subsection{Real-time PCR assay}

The real-time PCR was performed using the Bio-RAD/CFX384 Real-time PCR system (Bio-Rad, Hercules, CA) according to the manufacturer's instructions. The optimized PCR reaction system were as follows: $2 \mu \mathrm{L}$ DNA template, $10 \mu \mathrm{L}$ Go-tag qPCR Master Mix (Promega, Wisconsin, USA), $0.2 \mu \mathrm{L}$ of forward primer, $0.2 \mu \mathrm{L}$ of reverse primer (N-GPV-F and N-GPV-R, 20 $\mu \mathrm{mol} / \mathrm{L}$ ), and $7.6 \mu \mathrm{L}$ autoclaved nanopure water. Each reaction cycles comprised an initial activation step at $95{ }^{\circ} \mathrm{C}$ for $2 \mathrm{~min}$, followed by 40 cycles at $95{ }^{\circ} \mathrm{C}$ for $15 \mathrm{sec}, 60{ }^{\circ} \mathrm{C}$ for $1 \mathrm{~min}$. The fluorescence signal was collected during annealing/extension step. Ten-fold serial dilution concentrations of recombinant plasmid pMD-18T-ITR containing different copy numbers $\left(1 \times 10^{9}\right.$ to $1 \times 10$ DNA copies $/ \mu \mathrm{L}$ ) were used to generate the standard curve. Analysis of each assay was carried out using Bio-Rad CFX Manager (Bio-Rad, Hercules, CA) according to manual instructions.

\subsection{Sensitivity analys is}

The sensitivity analysis of real-time PCR and conventional PCR was determined 
by using different recombinant plasmid pMD-18T-ITR concentrations. pMD-18T-ITR template was prepared as follows: 10-fold serial dilution concentrations ranging from $1 \times 10^{9}$ copies $/ \mu \mathrm{L}$ to $1 \times 10$ copies $/ \mu \mathrm{L}, 2 \mu \mathrm{L}$ of each dilution sample was used as a template for specificity analys is, and each concentration of sample repeated two times, PCR products were visualized in $1.0 \%$ agarose gel provided by the manufacturer.

\subsection{Specificity and reproducibility analysis}

DNA from MDPV, GPV, N-GPV and other pathogens including DFV, NDV, AIV, DHV-1, DHV-3, R. a. and E. coli. was used to validate the specificity of the established real-time PCR assay for N-GPV detection. The reproducibility of real-time PCR assay was accessed by analyzing mean coefficient of variation (CV) by using serial dilution concentrations of pMD-18T-ITR $\left(10^{7}\right.$ copies $/ \mu \mathrm{L}, 10^{6}$ copies $/ \mu \mathrm{L}$, $10^{5}$ copies $/ \mu \mathrm{L}, 10^{4}$ copies $/ \mu \mathrm{L}$ ). The intra-assay variability of real-time PCR assay was accessed by using each dilution concentration in triplicate and comparing the coefficient of variation. The coefficient of variation expresses the standardized measure of dispersion with time for inter-assay variability.

\subsection{Animal experiments}

All procedures involving animal experiment were approved by the Institute of Animal Husbandry and Veterinary, South China Agricultural University, China. Sixty 1-day old Cherry Valley ducklings obtained from hatchery (Guiliu Fowl Company, Guangdong, China) were kept at experimental station under controlled conditions for acclimatization to the new environment. The ducklings were then randomly divided into treatment group and control group (30 ducklings/group), housed separately and bred in a parvovirus-free environment. All the ducklings were free of parvovirus-specific maternal antibodies confirmed by result of ELISA detection. For comparison, the ducklings in treatment group were injected intramuscularly with 500 $\mu \mathrm{L}$ of $\mathrm{AH}$ or GD viral allantoic fluid and the control group injected with $500 \mu \mathrm{L}$ PBS. The ducklings in treatment group and control group were kept for 4 weeks and all humane procedures and biosecurity guidelines were followed during experiment.

Three ducks from control group and Three ducks from treatment group were randomly selected and killed at each time point. Heart, liver, spleen, lung, kidney, 
pancreas, bursa of Fabricius, brain, excrement and blood from the ducks in control group and treatment group were analyzed by real-time PCR at $6 \mathrm{~h}, 12 \mathrm{~h}$, day 1, day 3 , day 7, day 14, day 21 and day 28 after virus infection.

In detail, obtained samples were homogenized in PBS $(20 \%$, w/v), viral DNA were extracted from tissue homogenates using Viral DNA/RNA Miniprep Kit (Axygen, New York, USA). The viral load of each sample was quantified using real-time PCR assay.

\section{Results}

\subsection{Establishme nt of real-time PCR standard curve}

For establishment of real-time PCR standard curve, the concentration of standard pMD-18T-ITR plasmid DNA was quantified $(344 \mathrm{ng} / \mu \mathrm{L})$ and $\mathrm{OD}_{260} / \mathrm{OD}_{280}$ of standard pMD-18T-ITR plasmid DNA was 1.90; the copy numbers of pMD-18T-ITR plasmid DNA were $8.7 \times 10^{10}$ copies $/ \mu \mathrm{L}$. The real-time PCR amplification curves were generated by pMD-18T-ITR plasmid DNA at the concentration $1 \times 10^{7}$ copies $/ \mu \mathrm{L}$, $1 \times 10^{6}$ copies $/ \mu \mathrm{L}, \quad 1 \times 10^{5}$ copies $/ \mu \mathrm{L}, \quad 1 \times 10^{4}$ copies $/ \mu \mathrm{L}, \quad$ and $1 \times 10^{3}$ copies $/ \mu \mathrm{L}$. The generated stand ard curve showed linearity with a slope of -0.3098 and the Y-intercept was 37.865, efficiency of standard curve was 0.995 (conducted by software of Bio-Rad CFX Manager (Bio-Rad, Hercules, CA) ) (Figure 1).

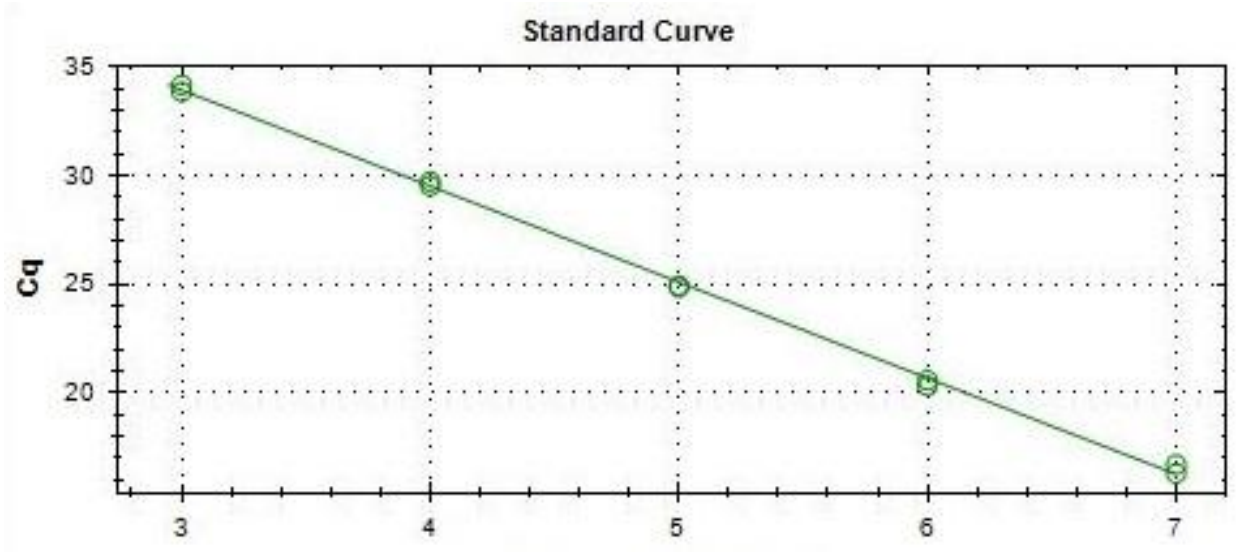

Figure 1. Establish the standard curve of pMD-18T-ITR plasmid DNA by real-time PCR.

Serial dilution concentrations of standard DNA ranging from $10^{7}-10^{3}($ copies $/ \mu \mathrm{L})$ were used. The slope of standard curve was -0.3098 , the Y-intercept was 37.865 , and efficiency of standard curve was 0.995 . 


\subsection{Sensitivity, specificity, reproducibility and dynamic range analysis of establis hed real-time PCR}

To evaluate the sensitivity of real-time PCR assay, serial dilution concentrations of pMD-18T-ITR plasmid DNA were used. The results showed that the detection limit of real-time PCR was 10 copies/reaction, the detection limit of conventional PCR was $1 \times 10^{4}$ copies/reaction; sensitivity of real-time PCR method was 1000-times higher than conventional PCR (10copies/reaction versus $1 \times 10^{4}$ copies/reaction) (Figure 2 and Figure 3).

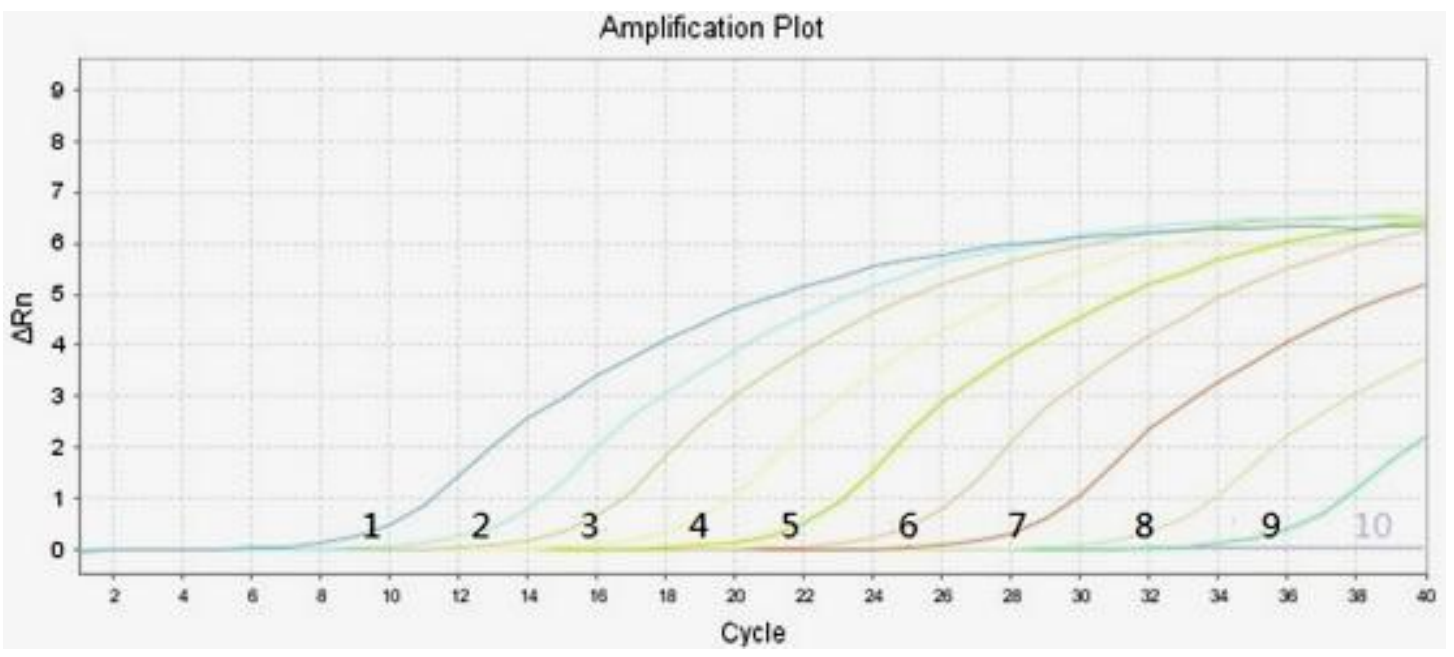

Figure 2. Amplification results of pMD-18T-ITR plasmid DNA by established real-time PCR for sensitivity verification. Ten-fold serial dilution concentrations of the DNA standard sample ranging from $1 \times 10^{9}$ copies $/ \mu \mathrm{L}$ to $1 \times 10^{1}$ copies $/ \mu \mathrm{L}$ were used. Number $1-9$ indic ated different DNA sample concentration in turn: $1 \times 10^{9}$ copies $/ \mu \mathrm{L}, 1 \times 10^{8}$ copies $/ \mu \mathrm{L}, 1 \times 10^{7}$ copies $/ \mu \mathrm{L}, 1 \times 10^{6}$ copies $/ \mu \mathrm{L}$, $1 \times 10^{5}$ copies $/ \mu \mathrm{L}, 1 \times 10^{4}$ copies $/ \mu \mathrm{L}, 1 \times 10^{3}$ copies $/ \mu \mathrm{L}, 1 \times 10^{2}$ copies $/ \mu \mathrm{L}, 1 \times 10^{1}$ copies $/ \mu \mathrm{L} ;$ number 10 : blank control).

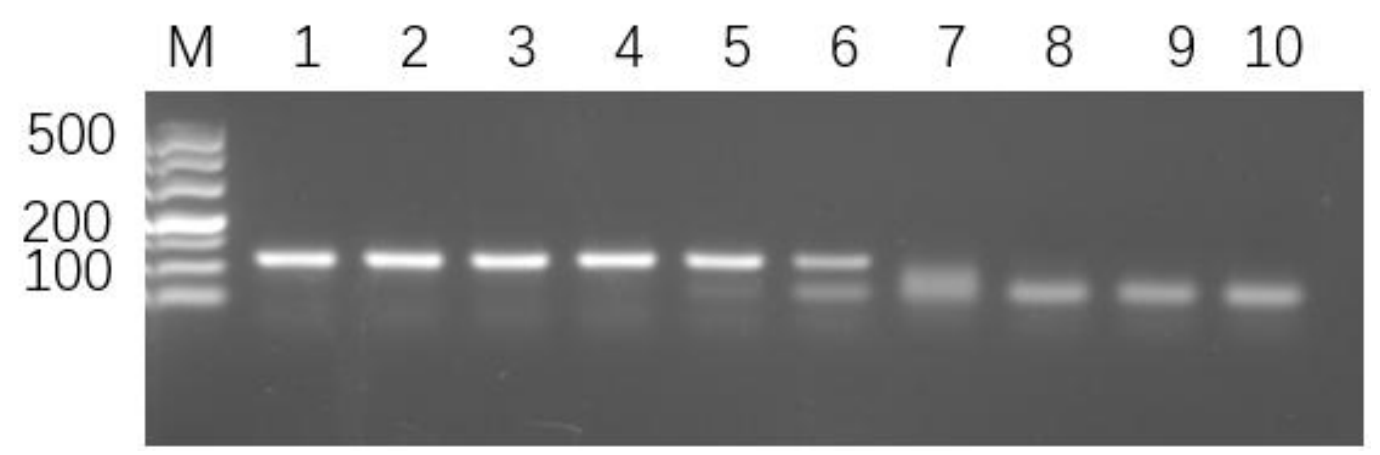

Figure 3. Results of conventional PCR for pMD-18T-ITR plasmid DNA detection for sensitivity verification. 
Ten-fold serial dilution concentrations of DNA standard samples ranging from $1 \times 10^{9}$ copies $/ \mu \mathrm{L}$ to $1 \times 10$ copies $/ \mu \mathrm{L}$ were detected by conventional PCR. Number $1-9$ indicated different DNA sample concentration in turn: $1 \times 10^{9}$ copies $/ \mu \mathrm{L}, 1 \times 10^{8}$ copies $/ \mu \mathrm{L}, 1 \times 10^{7}$ copies $/ \mu \mathrm{L}$, $1 \times 10^{6}$ copies $/ \mu \mathrm{L}, \quad 1 \times 10^{5}$ copies $/ \mu \mathrm{L}, \quad 1 \times 10^{4}$ copies $/ \mu \mathrm{L}, \quad 1 \times 10^{3}$ copies $/ \mu \mathrm{L}, \quad 1 \times 10^{2}$ copies $/ \mu \mathrm{L}, \quad 1 \times 10^{1}$ copies $/ \mu \mathrm{L}$; number 10: blank control.

To evaluate the specificity of real-time PCR assay, virus DNA (MDPV, GPV, N-GPV), virus cDNA (DFV, NDV, AIV, DHV-1, DHV-3), bacterial DNA ( $R . a ., E$. coli) and control (nuclease-free water) were used, the results demonstrated that there was a smooth amplification curve for N-GPV DNA, there were no amplification curve for virus DNA (MDPV, GPV), virus cDNA (DFV, NDV, AIV, DHV-1, DHV-3), bacterial DNA (R. a., E. coli) and control (nuclease-free water) (Figure 4).

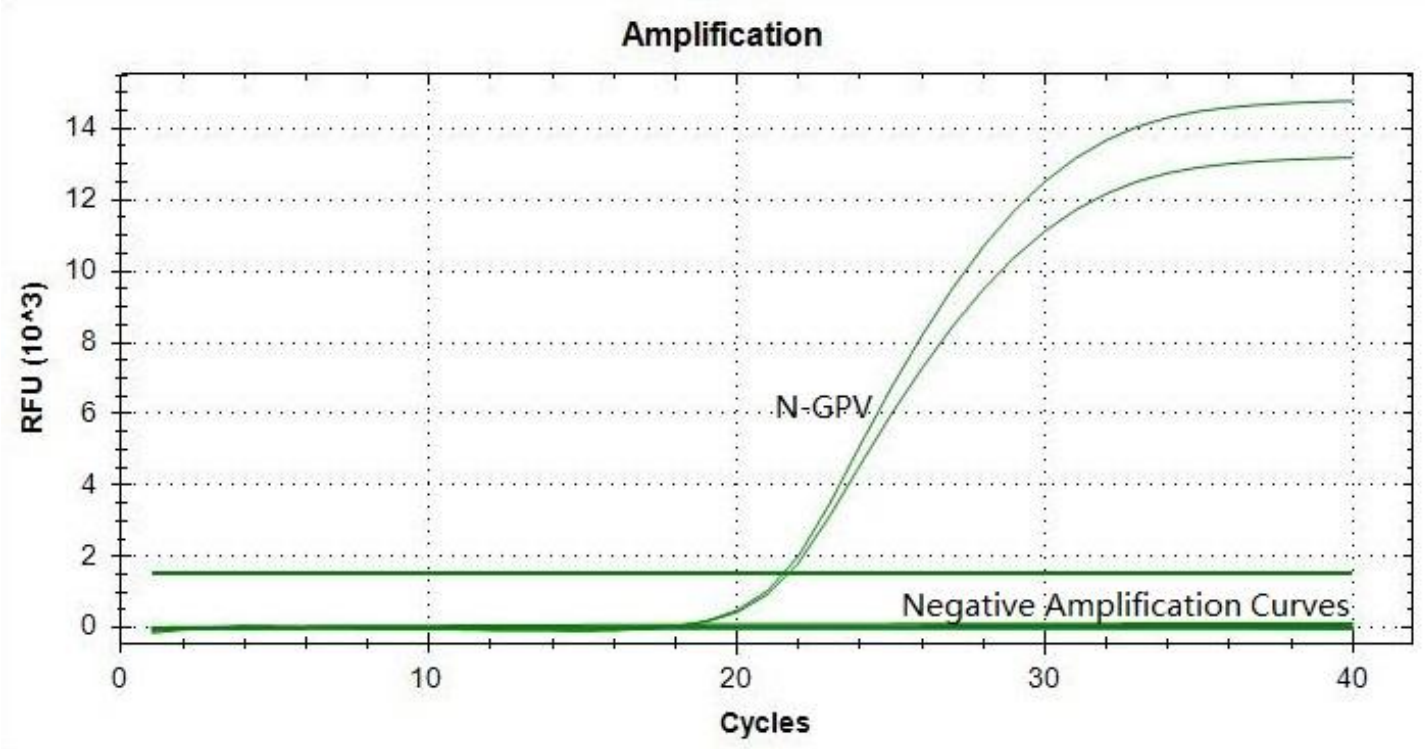

Figure.4 Specificity verification of the established real-time PCR. Nine DNA or cDNA samples from different viruses and bacteria (MDPV, GPV, DFV, NDV, AIV, DHV-1, DHV-3, $R$. $a$., E. coli ) were used to evaluate specificity of established real-time PCR assay.

For validation of repeatability of established real-time PCR assay, four different concentrations of standard DNA $\left(1 \times 10^{7}\right.$ copies $/ \mu \mathrm{L}, 1 \times 10^{6}$ copies $/ \mu \mathrm{L}, 1 \times 10^{5}$ copies $/ \mu \mathrm{L}$, $1 \times 10^{4}$ copies $\left./ \mu \mathrm{L}\right)$ were used, and every concentration of standard DNA repeated three times for statistics analysis. The results showed that The intra-assay CVs were in the range of $0.04-0.74 \%$, the inter-assay $\mathrm{CVs}$ were in the range of $0.16-0.53 \%$ (Table 2). These demonstrated that the established real-time PCR assay had a high 
reproducibility for N-GPV DNA detection.

Table 2. Reproducibility validation of established real-time PCR

\begin{tabular}{|c|c|c|c|c|c|c|c|c|}
\hline \multirow{2}{*}{ Samples } & \multirow{2}{*}{ Copies } & \multirow{2}{*}{$\mathrm{n}$} & \multicolumn{3}{|c|}{ Intra-batch (Ct Value) } & \multicolumn{3}{|c|}{ Inter-batch (Ct Value) } \\
\hline & & & Average & SD & $\mathrm{CV}(\%)$ & Average & $\mathrm{SD}$ & $\mathrm{CV}(\%)$ \\
\hline 1 & $10^{7}$ & 3 & 19.61 & 0.15 & 0.74 & 30.97 & 0.10 & 0.53 \\
\hline 2 & $10^{6}$ & 3 & 23.05 & 0.01 & 0.04 & 27.67 & 0.04 & 0.16 \\
\hline 3 & $10^{5}$ & 3 & 27.70 & 0.11 & 0.39 & 23.02 & 0.15 & 0.54 \\
\hline 4 & $10^{4}$ & 3 & 31.00 & 0.11 & 0.34 & 19.58 & 0.07 & 0.24 \\
\hline
\end{tabular}

\subsection{Dynamic distribution of N-GPV viral load in vivo using real-time PCR assay}

The reproductive properties of N-GPV AH in Cherry Valley ducks were analyzed by detection of viral load in blood, internal organs and ileac contents of infected ducks. The results showed that all tissues and blood isolated from infected ducks had high levels of viral load from $6 \mathrm{~h}$ to 28 days after quantification of N-GPV by using the established real-time PCR assay. The viral load of N-GPV presented a typical S-shaped curve accompanied with the passage of time, the highest viral load us ually reached at day 7 or day14 and the lowest viral load usually reached at day 1 or day 3 in all tissues and blood isolated from infected ducks.

In detail, the average value of N-GPV $\mathrm{AH}$ were $10^{5.76}$ in heart, $10^{5.08}$ in blood, $10^{3.35}$ in pancreas, $10^{5.34}$ in kidney, $10^{4.78}$ in spleen, $10^{4.10}$ in brain, $10^{5.64}$ in faeces, $10^{4.94}$ in liver, $10^{5.03}$ in lung, and $10^{5.07}$ in bursa of fabricius after infection for $6 \mathrm{~h}$.

The lowest point of viral load in these samples usually appears at day 1 (pancreas, spleen, liver, bursa of fabricius) or day 3 (heart, blood, kidney, brain, faeces, lung) and the average value was $10^{3.85}$ in heart), $10^{4.22}$ in blood, $10^{2.63}$ in pancreas, $10^{3.45}$ in kidney, $10^{2.96}$ in spleen, $10^{3.32}$ in brain, $10^{4.26}$ in faeces, $10^{3.64}$ in liver, $10^{4.06}$ in lung, $10^{2.75}$ in bursa of fabricius. The highest point of viral load appears at day 7 (blood, kidney, spleen, brain, liver, lung, bursa of fabricius), day 14 (faeces), day 21 (heart, 
pancreas) and the average value was $10^{7.43}$ in heart, $10^{8.01}$ in blood, $10^{6.05}$ in pancreas, $10^{7.22}$ in kidney, $10^{8.11}$ in spleen, $10^{5.91}$ in brain, $10^{6.43}$ in faeces, $10^{7.19}$ in liver, $10^{7.07}$ in lung, $10^{5.58}$ in bursa of fabricius (Figure 5). Those data demonstrated that real-time PCR assay was not only a powerful method for detection of the N-GPV AH in all kinds of tissues, excrement and blood from infected ducks, but also provided us a dynamic observation of the distribution of the N-GPV AH in all kinds of tissues in the body, which was of great significance in clinical diagnosis and clinical treatment.

A : Heart

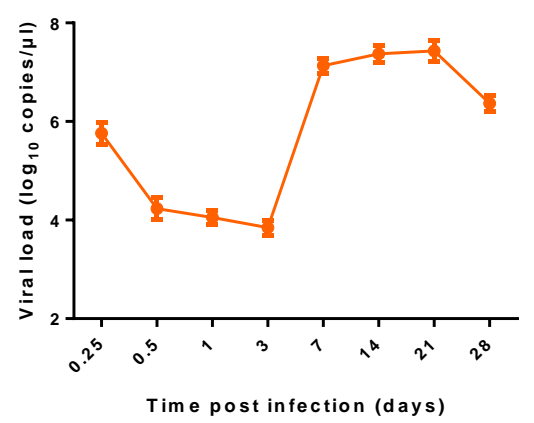

C: Pancreas

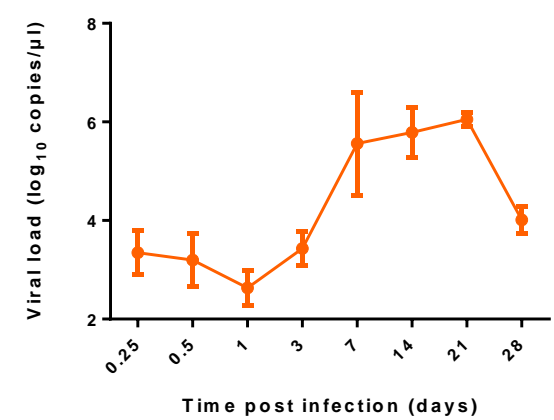

E: Spleen

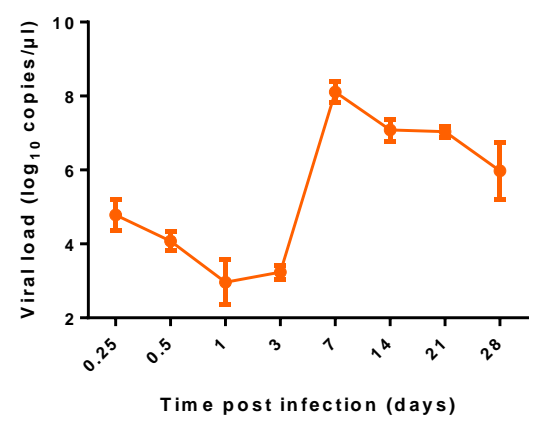

B : Blood

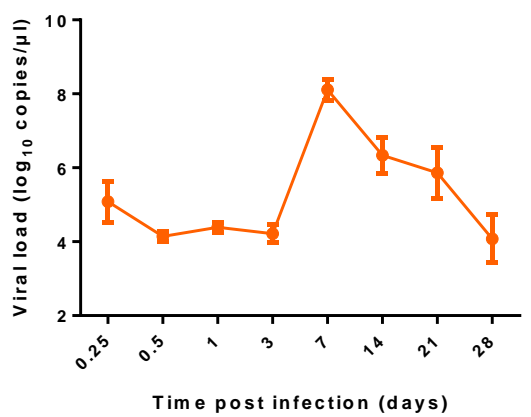

D : Kidney

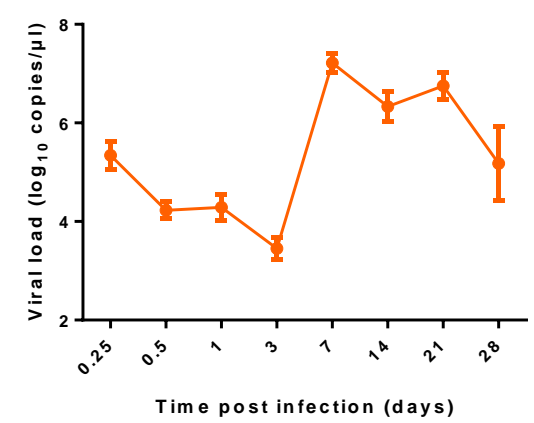

F : B rain

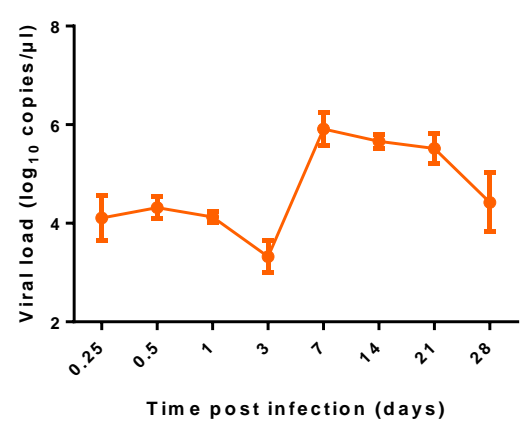



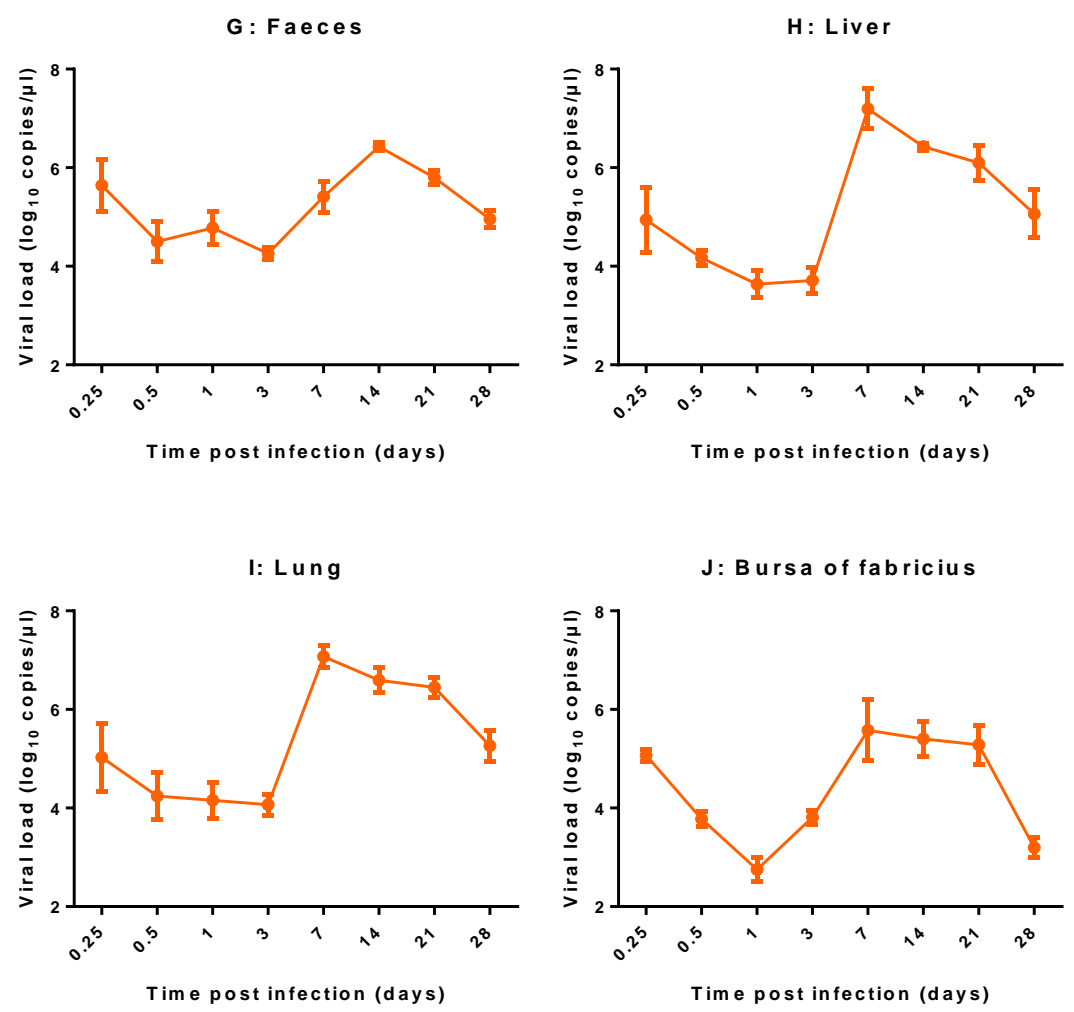

Figure 5. Detection results of viral loads in tissues (heart, liver, spleen, lung, kidney, pancreas, bursa of fabricius, brain), excrement and blood isolated from Cherry Valley ducks by the established real-time PCR assay at 6 h, 12 h, day 1, day 3, day 7, day 14, day 21 and day 28 after N-GPV AH infection. There were eight time points from $6 \mathrm{~h}$ to 28 days, the result of each time point were in triplicate, the data of viral loads showed as mean \pm SEM.

\section{Discussion}

SBDS in ducks was first reported in France in $1970 \mathrm{~s}^{[13]}$, followed by outbreaks in Taiwan (1989), Poland (1995) ${ }^{[21]}$, Hungary (2009) and mainland China $(2014)^{[22,23]}$. SBDS in ducks usually caused by GPV or MDPV, and co-infection with N-GPV and MDPV strains also existed; there were several variations among these parvovirus duck strains, the sequence analysis indicated that those N-GPV variations had higher homology among them compared with classical GPV and MDPV on the basis of phylogeny and homology analysis ${ }^{[24]}$.

There are many methods for the detection of GPV, N-GPV, MDPV, but those detection methods have their disadvantages. For example, virus isolation, electron microscopy, immunological-based assays which turned out to be laborious and 
time-consuming; conventional PCR assay and sequencing cannot effectively distinguish the various parvovirus strains because of highly homology at molecular or genomic level between GPV and N-GPV strains; Enzyme-linked immunoabsorbent assay (ELISA) methods based on VP3 protein are also applied in the detection of GPV and MDPV with a lower detection sensitivity ${ }^{[25,26]}$; Loop-mediated isothermal amplification (LAMP) assay is also developed for rapid, accurate, sensitive and convenient detection of MDPV and GPV, but this method always obtains high number of false positive results ${ }^{[27]}$.

Here, we developed a real-time PCR assay for the quantification of N-GPV genome copies in ducks and found that this method is highly sensitive, specific and reproducible compared with conventional PCR. Moreover, the real-time PCR assay can be used for simultaneous detection and quantification of DNA. It allowed us to study the pathogenesis of disease and mechanisms of virus transmission by investigation of viral dynamics. The assay can also be used for quantification of viral load in different tissues at various times after infection; the data of viral load could be useful for multi-aspect understanding of viruses. Compared with other studies, this research reported the distribution and quantity of N-GPV and its characteristic lesions in infected muscovy ducks, which was of great significance in clinical diagnosis and clinical treatment.

The viral load of N-GPV presented a typical S-shaped curve accompanied with the passage of time, the highest viral load usually reached at day 7 or day 14 and the lowest viral load usually reached at day 1 or day 3 in all tissues and blood isolated from infected ducks. It may be because after entering the body, the virus needs an adaptation process to overcome the resistance against disease due to body's immune system.

In summary, we had established a sensitive, specific and reproducible real-time PCR assay for N-GPV detection, it could be suitable for parvovirus detection and quantification simultaneously, and we could observe and analyze the dynamic distribution of N-GPV viral load by established real-time PCR assay in vivo, which was of great significance in clinical diagnosis and clinical treatment. 


\section{Conflict of interests}

The authors declare that they have no competing interests in this article.

\section{Acknowledgements}

None.

\section{Funding}

None.

\section{References}

1. Sirivan P, Obayashi M, Nakamura M, Tantaswasdi U, Takehara K: Detection of goose and Muscovy duck parvoviruses using polymerase chain reaction-restriction enzyme fragment length polymorphism analysis. Avian Diseases 1998, 42(1):133-139.

2. Niu Y, Zhao L, Liu B, Liu J, Yang F, Yin H, Huo H, Chen H: Comparative genetic analysis and pathological characteristics of goose parvovirus isolated in Heilongjiang, China. Virology Journal 2018, 15(1):27.

3. Kisary J, Derzsy D, Meszaros $\mathrm{J}$ : Attenuation of the goose parvovirus strain $B$. Laboratory and field trials of the attenuated mutant for vaccination against Derzsy's disease. Avian Pathology Journal of the Wvpa 1978, 7(3):397-406.

4. Wang J, Duan J, Meng X, Gong J, Jiang Z, Zhu G: Cloning of the genome of a goose parvovirus vaccine strain SYG61v and rescue of infectious virions from recombinant plasmid in embryonated goose eggs. Journal of Virological Methods 2014, 200(10):41.

5. Yu K, Ma X, Sheng Z, Qi L, Liu C, Dan W, Bing H, Feng L, Song M: Identification of Goose-Origin Parvovirus as a Cause of Newly Emerging Beak Atrophy and Dwarfism Syndrome in Ducklings. Journal of Clinical Microbiology 2016, 54(8):1999.

6. Brown KE, Green SW, Young NS: Goose Parvovirus-An Autonomous Member of the Dependovirus Genus? Virology 1995, 210(2):283-291.

7. Tatár-kis T, Mató T, Markos B, Palya V: Phylogenetic analysis of Hungarian goose parvovirus isolates and vaccine strains. Avian Pathology 2004, 33(4):438-444.

8. Le GRG, Jestin V: Biochemical and genomic characterization of Muscovy duck parvovirus. Archives of Virology 1994, 139(1-2):121-131. 
9. Glávits R, Zolnai A, Szabó É, Ivanics É, Zarka P, Mató T, Palya V: Comparative pathological studies on domestic geese (Anser anser domestica) and Muscovy ducks (Cairina moschata) experimentally infected with parvovirus strains of goose and Muscovy duck origin. Acta Veterinaria Hungarica 2005, 53(1):73.

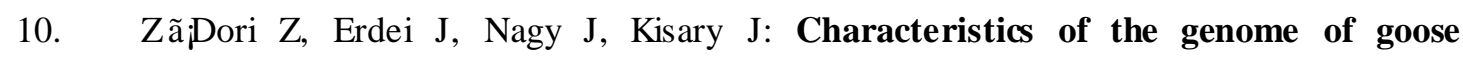
parvovirus. Avian Pathology 1994, 23(2):359-364.

11. Z Z, R S, T R, J K: Analysis of the complete nucleotide sequences of goose and muscovy duck parvoviruses indicates common ancestral origin with adeno-associated virus 2. Virology 1995, 212(2):562-573.

12. Palya V, Zolnai A, Benyeda Z, Kovács E, Kardi V, Mató T: Short beak and dwarfism syndrome of mule duck is caused by a distinct lineage of goose parvovirus. Avian Pathology 2009, 38(2):175.

13. Palya V, Zolnai A, Benyeda Z, Kovács E, Kardi V, Mató T: Short beak and dwarfism syndrome of mule duck is caused by a distinct lineage of goose parvovirus. Avian Pathology Journal of the Wvpa 2009, 38(2):175.

14. Chen S, Wang S, Cheng X, Xiao S, Zhu X, Lin F, Wu N, Wang J, Huang M, Zheng M: Isolation and characterization of a distinct duck-origin goose parvovirus causing an outbreak of duckling short beak and dwarfism syndrome in China. Archives of Virology 2016, 161(9):2407.

15. Li P, Lin S, Zhang R, Chen J, Sun D, Lan J, Song S, Xie Z, Jiang S: Isolation and characterization of novel goose parvovirus-related virus reveal the evolution of waterfowl parvovirus. Transboundary \& Emerging Diseases 2017, 65(2).

16. V P, A Z, Z B, E K, V K, T M: Short beak and dwarfism syndrome of mule duck is caused by a distinct lineage of goose parvovirus. Avian pathology : journal of the WVPA 2009, 38(2):175.

17. Yu H: The advances and application of Fluorescence Quantitative Polymerase Chain Reaction (real-time PCR ). Guizhou Agricultural Sciences 2009:29-32.

18. Shien JH, Wang YS, Chen $\mathrm{CH}$, Shieh $\mathrm{HK}$, Hu CC, Chang PC: Identification of sequence changes in live attenuated goose parvovirus vaccine strains developed in Asia and Europe. Avian Pathology Journal of the Wvpa 2008, 37(5):499. 
19. Guo Y, Cheng A, Wang M, Shen C, Jia R, Chen S, Na Z: Development of TaqMan ${ }^{\circledR}$ MGB fluorescent real-time PCR assay for the detection of anatid herpesvirus 1 . Virology Journal 2009, 6(1):71-71.

20. Pantchev A, Sting R, Bauerfeind R, Tyczka J, Sachse K: New real-time PCR tests for species-specific detection of Chlamydophila psittaci and Chlamydophila abortus from tissue samples. Veterinary Journal 2009, 181(2):145-150.

21. Woźniakowski G, Kozdruń W, Samoreksalamonowicz E: Genetic variance of Derzsy's disease strains isolated in Poland. Journal of Molecular \& Genetic Medicine An International Journal of Biomedical Research 2009, 3(2):210.

22. Chen H, Dou Y, Tang Y, Zhang Z, Zheng X, Niu X, Yang J, Yu X, Diao Y: Isolation and Genomic Characterization of a Duck-Origin GPV-Related Parvovirus from Cherry Valley Ducklings in China. Plos One 2015, 10(10):e0140284.

23. Kisary J: Diagnosis and Control of Parvovirus Infection of Geese (Derzsy's Disease); 1986.

24. Fu Q, Huang Y, Wan C, Fu G, Qi B, Cheng L, Shi S, Chen H, Liu R, Chen Z: Genomic and pathogenic analysis of a Muscovy duck parvovirus strain causing short beak and dwarfism syndrome without tongue protrusion. Research in Veterinary Science 2017, 115:393.

25. Zhang Y, Li Y, Liu M, Zhang D, Guo D, Liu C, Zhi H, Wang X, Li G, Li N: Development and evaluation of a VP3-ELISA for the detection of goose and Muscovy duck parvovirus antibodies. Journal of Virological Methods 2010, 163(2):405-409.

26. Ju HY, Wei N, Shang XZ, Jing ZQ, Guo L, Ma B, Wang JW: Prokaryotic expression of VP3 gene of goose parvovirus wild strain and detection of antigenicity of the expressed protein. Chinese Veterinary Science 2009:492-497.

27. Yang JL, Rui Y, Cheng AC, Wang MS, Fu LZ, Yang SQ, Zhang SH, Liu Y, Xu ZY: A simple and rapid method for detection of Goose Parvovirus in the field by loop-mediated isothermal amplification. Virology Journal 2010, 7(1):14-14. 